\title{
Reflections on the SWSEEL Russian program from a sociocultural perspective: Challenges and benefits
}

\author{
Martina M. Barnas \\ Snezhana Zheltoukhova
}

\begin{abstract}
The SWSEEL intensive language summer training program held annually at the Bloomington campus of Indiana University is one of the oldest and most popular intensive Russian language programs in the US. In this paper we reflect on our respective combined experience as a Russian course learner and a Russian course instructor to identify benefits and potential challenges from the perspective of sociocultural learning theories as developed in the field of Learning Sciences. We show the sociocultural lens is well suited for describing learning in the SWSEEL environment, and the Russian SWSEEL course is designed and taught in agreement with perspectives of learning in sociocultural learning theories. Ultimately, sociocultural instructional strategies strengthen the SWSEEL model and validate the application of sociocultural learning design in the context of intensive language programs.
\end{abstract}

\section{Introduction}

Since its inception in 1950, the summer intensive language workshop SWSEEL held annually at the Indiana University, Bloomington has grown into one of the most well-known intensive language programs in the country. This paper presents a first step toward the examination of the program through the lens of sociocultural learning theories, as understood by the field of Learning Sciences, a multidisciplinary field in education research that empirically studies learning as it exists in real world settings, and also how learning can be better facilitated (Sawyer, 2005). Central to education is the concept of knowledge. Since knowledge is not a tangible object, it relies on philosophy to give it its meaning. For this reason, there are varied approaches to understanding learning, but the consensus in the field is that they generally fall into one of three categories (see Case, 1996; Greeno, Collins, \& Resnick, 1996) rooted in three different epistemologies (for a review see Bredo, 2006), each emphasizing a different aspect of learning. We argue that one of the epistemologies-namely the sociocultural perspective of learning (Brown, Collins, \& Duguid, 1989; Greeno \& Middle School Mathematics Through Applications Project Group, 1998), which has its roots in the work of Soviet psychologist Lev Vygotskyprovides a particularly suitable framework for a description of the learning process in an intensive Russian course. It is important to acknowledge that sociocultural (Vygotsky, 1987) and/or cultural-historical activity (Leont'ev, 1974) theory has influenced second language acquisition (SLA) research directly and profoundly (see Lantolf, 2000; Lantolf and Thorne, 2007; Thorne, 2005); however, a review of SLA 
research is outside of the scope of this article. Instead we reflect on our experiences from the point of view of Learning Sciences.

Furthermore, during the preparation of this article, questions have arisen that are also beyond the scope of this paper. For example, as we will document later, teachers in the program are given considerable autonomy, yet the system is remarkably consistent and cohesive. This points to the important role of the organizers, and the interplay between the structure of the program and its various actors, which is of interest on its own. In this first study, we reflect on the combined experience of a learner and a lecturer of the program at a broad level, without distinguishing between the actors and the structure.

This paper is organized as follows: first we briefly review the fundamentals of the sociocultural view of learning in Learning Sciences, which establish a theoretical prism for our analysis. Next we describe the Russian SWSEEL program, drawing on our combined experiences with the Level 5 and Level 6 Russian courses in which we, the authors, participated as a student (Barnas) and an instructor (Zheltoukhova), respectively. We then reflect on our experience, identify numerous benefits, acknowledge potential challenges for learners and instructors within the context of an intensive summer language course, and offer some practical suggestions inspired by input from sociocultural learning theories to improve learning in this environment. We conclude with a call for research to be done in multiple learning issues within the context of intensive Russian programs from the sociocultural perspective.

\section{Overview of Fundamentals of Sociocultural Learning Theories}

The philosophical foundations of sociocultural approaches are based on the dialectic epistemologies of Hegel, Marx, and their followers. As Case (1996) states, knowledge "has its primary origin in the social and material history of culture" (p. 79), which constitutes a rejection of the rationalist view that puts emphasis on an individual, rather than a group. However, Greeno (1997) argues that the sociocultural perspective is a synthesis encompassing previous perspectives, and accommodates practices centered on an individual. Sociocultural theories stem from the work of Vygotsky (Case, 1996), who was active in the Soviet Union in the 1930s but whose work did not gain influence globally until post mortem. Vygotsky (1978) pointed out that through interaction with more knowledgeable adults or peers, children's capabilities are extended beyond what they would be able to do without help, a concept known as the zone of proximal development (ZPD).

Some elements of Vygotsky's work were met with criticism, which led to modified theories by neo-Vygotskian scholars. For example, tools are seen as having a specific, rather than general, effect on capabilities. While Vygotsky considered language the most important milestone, contemporary neo-Vygotskian theories recognize the importance of notational systems as a vital class of intellectual tools. The unique contribution of sociocultural approaches is the recognition of "cognitive apprenticeship" (Rogoff, 1990), a practice in line with the assumption that intelligence is socially distributed, rather than confined to an individual. 


\section{Cognitive Apprenticeship}

The sociocultural perspective does not view a learner in isolation; rather, the learner is perceived as a part of community. Thus, one form of knowing is demonstrated through the ability of the entire group to perform cooperative activities. This collective knowing is complementary to individual knowing, i.e., the ability of an individual to participate in the group activity. Learning is perceived as strengthening the abilities of individuals to participate in a community, or as Greeno (1997) puts it, "a progress along trajectories of participation and growth of identity" (p. 9). A question is whether the peripheral participation of beginners is legitimate. An environment of apprenticeship (Rogoff, 1990) is supposed to allow for such participation. However, to be in a productive environment for learning, learners need to have opportunities to observe and practice in a way that strengthens their abilities.

The sociocultural perspective is broad and encompasses a rich spectrum of interactive components, as seen in seminal articles by Brown et al. (1989), Greeno et al. (1998), and Pea (1993), who each explore different sociocultural perspectives of knowledge and learning. Brown et al. (1989) focus on how activity and situations are integral for learning, and point out that it is impossible to separate what is learned from how it is learned. By ignoring this, education defeats its purpose of providing robust, useable knowledge. Cognitive apprenticeship provides an alternative that emerges from research on cognition and learning. The key element of the proposed approach is authentic practice, which is distinct from the typical school practice. Authentic practice is defined as ordinary practices of the culture. Brown et al. (1989) point out the artificiality of many school activities. The authors argue that authentic activities are not restricted to experts, and that novices can participate via apprenticeship.

\section{Distributed Intelligence}

According to Pea (1993), knowledge is socially constructed in interactions, and intelligence can be distributed for use in diverse artifacts. Artifacts range from physical tools to notational systems (e.g., algebraic expressions). Environments which humans create are thick with such artifacts. The concept of distributed intelligence arises in contrast to the concept of intelligence as an attribute of an individual, referring to the individual's mental representations. Distributed intelligence manifests in activity, which is enabled by intelligence, but not just the intelligence of one individual. Tools and artifacts can advance activity. Pea distinguished two types of distribution of intelligence: social and material. Social distribution comes from the construction of intelligence in social interactions; material distribution refers to the invention of uses or the exploitation of affordances of artifacts.

Pea (1993) recognizes that distributed intelligence can be augmented with computing, e.g., by creating malleable virtual realities for modeling and reasoning, including visualization programs characterized by guided participation that distributes intelligence across child and adult, employing inscriptional systems such 
as scientific symbols and mathematical representations, and with situated cognition that is, according to Pea, "highly inventive in exploiting features of the physical and social situations as resource" (p. 63).

Greeno et al. (1998), for their part, concentrate on socially organized interactions, and propose that the situative perspective offers a view of learning beyond limitations of the cognitive (rationalist), while acknowledging that studies of individual cognition and interactional cognition exhibit strengths and weaknesses. The authors formulate generalizations of cognitive concepts of schemata, meaning, and engagement, but recognize that one challenge for the study of socially organized interactions is the necessity of dealing with complex systems.

\section{Learning Communities}

The theory of learning translates into educational design. Generally speaking, the favored method in the sociocultural perspective is to create a community of authentic practice in the learning environment and initiate learners into it (Case, 1996). For example, learners work in small groups, and as their understanding deepens, so does their ability to communicate it. As discussed in Greeno et al. (1996), sociocultural theories view learning as an increase in the ability to participate in distributive cognitive systems. The individual's identity derives from participation in communities. Notwithstanding this, the authors acknowledge that "effective learning involves being strongly engaged in activities that capture learners' interests because of their intrinsic qualities as well as participation in communities" (p. 26). Moreover, while some individuals may become strongly engaged in activities that are dominated by group interaction, the view does not disregard those for whom the activity is primarily a solitary pursuit, and their personal immersion defines their social role. From the situative view, curricula should concentrate on activities that students should learn to participate in, as well as subject matter. One aspect of this is organizing the curriculum of the subject matter in a way that students come to appreciate and learn to participate in authentic discourses (Greeno et al., 1996).

Sociocultural perspectives offer a pragmatic approach for fostering engagement. From a sociocultural perspective, an individual is never an isolated entity. She is inseparable from the community, and this concept includes tools and artifacts, all of which carry knowledge. Knowing is the ability to participate in activities of the community. Community plays a crucial role in engagement or motivation.

\section{Productive Engagement}

Engle and Conant (2002) present four design principles that were formulated $a$ posteriori to account for the success of productive disciplinary engagement in a specific classroom. These principles identify underlying regularities in what the teachers, curriculum, and learning designers did that may explain students' engagement. While these principles were inferred in a specific content domain (biology), they are sufficiently general to be useful in other content areas. The four 
guiding principles that the authors inferred are problematizing content, giving students authority, holding them accountable to others and to disciplinary norms, and providing relevant resources.

Crucial for productive engagement and any productive learning is the element of assessment. The sociocultural view provides a broader, more situated and contextually significant perspective of assessment than other perspectives of learning. According to Greeno et al. (1996), since from the sociocultural view knowing is seen as an ability to participate in socially distributed practices, assessment should evaluate this ability. Some alternative assessment practices that are acceptable from this point of view are evaluation as a direct result of an inquiry or observation of the work of groups or an individual in a group. Greeno et al. (1996) also suggest that students should be participants in the assessment, beyond being assessed. An example of meaningful participation of students in the assessment process is the students' contribution to the formulation of standards. Hickey and Anderson (2007) offer a comprehensive and practical multilevel assessment framework. They cover assessment from the immediate level-i.e., teacher monitoring and refining discourse via informal observation of a specific curricular event-to the remote-i.e., norm-referenced tests to determine national achievement that should provide input for policymakers to formulate long-term policies on broad achievement targets.

In summary, the sociocultural view of how an individual learns is that it is never an endeavor carried out in isolation. To understand learning and to design effectively to achieve it, consideration must be given to the community and the environment. The environment includes tools and artifacts, such as technology, books, and notational systems, all of which carry intelligence. Participation in a community activity fosters engagement and motivation; however, this does not negate the need for a learner's intrinsic interest in the activity. The sociocultural learning theories, seen as a synthesis and a generalization, rather than an antithesis of learning theories focused solely on an individual, broaden the perspective on assessment as well. Such sociocultural instructional design acknowledges the need for various assessment instruments without the extremes of overreliance on any single one, or rejecting any. It posits that each vehicle has its merits when used appropriately.

\section{An Intensive Summer Russian Program from the Sociocultural Perspective}

We argue that the SWSEEL intensive summer language course, held annually at Indiana University, Bloomington, exhibits sociocultural principles reviewed in the first part of the article. Notably, the sociocultural perspective, rather than an associationist or constructivist view, aligns with the recently developed sociolinguistic theories of L2 acquisition (see Tarone, 2007). In the following section we describe features of the SWSEEL intensive summer language program as a synthesis of the views of both a learner and an instructor. We share our reflections as a sixth-level Russian language student in summer 2013 and a fifth-level Russian 
language instructor in the summers of 2012 and 2013, to identify challenges and benefits of the SWSEEL approach to intensive language learning.

\section{SWSEEL: Summer Language Workshop}

In the summer of 2013, at least 19 intensive summer Russian language programs operated at universities and colleges in the US, offering a variety of levels of instruction (www.aatseel.org). Founded in 1950, Russian SWSEEL offers one of the oldest intensive summer Russian language programs in the United States. In recent years the number of SWSEEL students learning Russian has fluctuated between approximately 100 and 130 per summer. In summer 2013, the Russian program had 20 faculty and about 110 students. The defining characteristic of such a program is the fact that it provides the opportunity for participants to cover the material of two academic semesters of study in eight or nine weeks of daily classes. Students may complete the first four weeks of study as the equivalent of one academic semester. SWSEEL credits are transferable to other academic institutions. The program is not limited to a particular cohort of students; rather, it is designed for domestic and international undergraduate and graduate students, professionals, and exceptional high school students over age 17. Students are grouped according to their placement test results into different levels. Some proficiency levels may require more than one group, since the size of the group is kept relatively small, with the maximum capped at 18 students. Thus, for example, in 2013 the largest group had 14 students. The Russian program at SWSEEL offers nine levels of Russian, varying from novice to advanced.

Curricular design includes a placement test, a post-test and three to five academic hours in a classroom setting every workday. Classroom hours are divided between four instructors whose primary foci are grammar, conversation, listening, and phonetics, respectively. The fact that there is a separate phonetics module is significant; to our knowledge, it is one of the distinguishing features of SWSEEL in comparison with other similar programs.

Grammar instructors are each assigned to one specific group for the duration of the course, and spend three hours with their students a day. Conversation instructors work with each group four academic hours a week. Listening and phonetics instructors teach each group for two academic hours a week. Grammar, conversation, and listening instructors involved with the same group coordinate their efforts to create a cohesive program. For example, they share their syllabi, and keep topics, vocabulary, and grammar coordinated according to the shared textbook. Phonetics instructors have different overarching topics each week, such as "vowel reduction" and so forth. In other words, their focus is on a much smaller scale of elements of language. There may or may not be some coordination with the grammar instructors, since it is not needed for the efficiency of the course.

Daily homework is an important part of the curriculum at SWSEEL. As a rule, the grammar section instructors assign the majority of the homework, with the phonetics, conversation, and listening instructors contributing only $10 \%$ to $20 \%$ of the total amount of homework. Daily grammar homework typically consists of 
learning vocabulary for the next day, and of grammar exercises from a textbook, but may instead involve a creative writing assignment. Students are encouraged, but not required, to write the entire exercise, rather than simply fill in blanks, to practice their writing skills. The instructors have a considerable amount of autonomy regarding classroom materials. One major textbook is usually regulated by the SWSEEL Russian program administration, while the rest of the materials are created or provided by instructors according to their teaching goals.

Extracurricular activities include "Russian table," a biweekly lunch gathering that facilitates informal conversation among program participants. Attendance at Russian table is strongly encouraged, to the extent that it appears mandatory for students enrolled in all levels of the program. Additional extracurricular activities are comprised of lectures in the target language, film screenings, and a number of interest-based clubs (theater, choir, poetry club, Russian radio etc). This program is enhanced by one-time events such as a talent show (organized in collaboration with other language programs) or food tastings. While participation in extracurricular activities is not mandatory, for students of higher proficiency levels, some activities, most notably the Russian film screenings and lectures, may be incorporated into homework assignments for the mandatory classroom components (conversation and listening) in order to encourage attendance.

\section{Sociocultural Principles Observed in the SWSEEL 2013 Russian Summer Intensive Program}

We will now apply the sociocultural perspective of learning to the SWSEEL 2013 Russian program, based on our observations as student and teacher. The authors regularly met during the eight weeks of the program and exchanged their reflections in order to situate them within a sociocultural framework.

\section{Knowledge as the ability to participate in a group activity}

This view of knowledge is exactly the implicit view of knowledge that underlies the design of intensive courses. The aim of an intensive course is to enable a learner to communicate in the target language and effectively participate in group activities, with the ultimate goal of being able to engage with a community of L1, or native, speakers.

The SWSEEL Russian curriculum includes a conversation component in addition to communicatively based grammar classes. Such curricular design aims to provide adequate training for future use of the language by students in their personal and professional lives. As a result, intensive language courses are popular among students who intend to study abroad, as well as among Reserve Officers Training Corps (ROTC) students.

The curricular design implies several classroom hours with the same group of colearners daily, in contrast with a typical academic year language classroom or tutoring. As a result, group activities become the main tool for language learning at both the microlevel of one academic hour and the macrolevel of overarching projects that span several weeks. Implementation of macrolevel project-based 
learning is enhanced by collaboration between grammar, conversation, listening, and phonetics instructors who work with the same group of students. Specifically, instructors of Level 5 exchanged emails sharing their weekly plans, requests, and suggestions for each other. For example, two times out of eight, oral parts of weekly grammar tests were conducted by the conversation instructor during his office hours.

Such projects were enhanced by extracurricular programming. For instance, fifth-level students in 2012 and 2013 wrote and performed original plays as part of their study of law/criminal vocabulary. First they mastered the vocabulary during grammar- and vocabulary-oriented classroom hours. Then, during conversation classes they were given the task of collaboratively creating an original play with a mystery plot. Conversation and grammar instructors provided classroom time for rehearsals and guided the groups through the entire process of creating a theatrical performance. All groups rehearsed their plays in front of the audience at least once during class time, and some performed their plays voluntarily at an all-program talent show. The collaboration of instructors was crucial for the implementation of this project to guarantee efficient organizing, time framing, adequate support, and so forth. As a result, effective learning is enhanced by participation in group activities.

\section{Learning as an increasing ability to participate in a particular community of practice}

The target community of practice in language studies is a community of native speakers. Intensive courses clearly provide a trajectory that gets closer and closer to the language skill of L1 speakers and an understanding of their culture. While at first the learners need to master basics of the target language, as their proficiency increases, the cultural component needs to be implemented. This is often achieved in a classroom environment through a literature component, or through informative articles describing certain aspects of life (see, for example, a textbook used for the Russian SWSEEL Level 6 by Rifkin, 1996), which are used as a context for extending vocabulary and grammar.

The informal part of the SWSEEL intensive course, particularly the interestbased clubs, expands on classroom learning. For example, students of all levels of Russian, including beginners, had the opportunity to participate in a Russian radio club. The goal was to collaboratively prepare and conduct weekly radio shows as DJs and music programmers with the minor mediation of an instructor. Rising to the challenge, students of the second and third levels expressed their willingness to participate in this club, sharing the responsibilities equally with higher-level students. As a result, despite a noticeable knowledge gap, these mixed-skill-level groups successfully prepared and conducted radio shows. This informal learning environment gave rise to a cognitive apprenticeship (Rogoff, 1990).

The first task for the DJs was to create an advertising poster, and this task was manageable even for lower-level students of Russian. The second task was to prepare a playlist of songs weekly, and this task was manageable as well, due to the 
fact that Russian music is readily accessible on the Internet. For example, a search for "Russian rap" on YouTube yields several links to songs in Russian. As a result, DJs create a community by collaborating on producing a show and communicating with each other and with listeners of the show in Russian. This club successfully satisfied the often daunting demand for any apprenticeship model (Rogoff, 1990) that the participation of beginners, which is of necessity peripheral, be meaningful (Greeno et al., 1996). The context of an authentic radio studio facilitated the development of specific aspects of language and communication skills.

Another salient example is the Russian drama circle in SWSEEL 2013, which was led by three instructors. As in the previous example, students of varied skill levels were willing to participate in this club (Levels 2-6). The successful completion of the project (i.e., performance of the play during the Talent Showcase at the end of the program) could be analyzed using the important Vygotskian construct of ZPD. In terms of Vygotskian concepts, all student activities during drama circle meetings were other-regulated by the instructors, but were developed in self-regulated activities, and expanded the ZPD for the future L2 language development of learners.

Despite the benefits of apprenticeship seen in interest-based clubs, we should be aware of possible challenges for students. Time management is one such challenge, as many students experience difficulties in finding a good balance between informal activities and required work. Thus, it is important that interest clubs not be a part of formal program requirements, which allows students to define their own level of involvement in extracurricular programming without jeopardizing their overall language learning progress.

\section{Importance of authentic practice}

An important principle distinguishing sociocultural perspectives from all other perspectives of learning is the emphasis on authentic practice. According to the sociocultural perspective, authentic practice is defined as an ordinary practice of the culture, which is often different from a typical school activity. While the importance or even feasibility of using authentic practices for learning in schools in fields like mathematics or history can be debated, in language learning, especially at the more advanced levels, the importance of adopting authentic practices is undeniable. For example, many common American cultural practices such as smiling or complimenting strangers, or the way we phrase requests, would be perceived in Russia as intrusive, rude, or could be misinterpreted entirely. A target-language speaker might use correct words but not in a culturally correct context, and this potential issue can only be averted by using authentic practices when learning the target language. Such practices are taught effectively by L1 Russian-speaking instructors who teach higher levels of the program.

An example of how authentic cultural practices were brought into the subject matter was a unit on Russian telephone etiquette, which was part of the curriculum of Level 6 in 2013. This was achieved through a variety of activities coordinated by grammar, listening, and conversation instructors. The activities included role- 
playing phone conversations, inspired by a recent amusing news event, watching (and listening to) a Russian comedian's performance in the form of a phone conversation during grammar class, recognizing phone numbers as they are pronounced by L1 speakers during listening class, and a continued discussion of Russian phone etiquette during the conversation class.

Often authentic practices and cultural insight are brought into the learning environment through the use of authentic literary texts. The downside, or at least a challenge, is that not all learners connect well with what they perceive as literary study. The sociocultural perspective offers an insight and a recommendation. Students are more motivated if the context is something that they already have an interest in. Therefore, if students are allowed autonomy in choosing projects, they can be exposed to the cultural aspects in a way that they may find engaging.

\section{Distributed intelligence}

Recently, using technology as an authentic learning tool in a language classroom became not only desirable, but inevitable due to the increased capability and accessibility of Internet resources and information technologies. According to Pea (1993), computing promotes both social and material intelligence distribution. Thus, contemporary intensive language programs in general, and SWSEEL in particular, extensively use various information technology resources in language classrooms. For example, grammar instructors incorporated various Internet resources in their classrooms, including the social network for education, www.lore.com, as a virtual space for discussion forums. To increase their willingness to engage, students could choose their imaginary identities while answering forum questions. The imaginary identities allowed them to practice language skills while maintaining personal boundaries. During breaks between classes, students enjoyed streaming current news from Russia, thanks to on-line TV (www.1tv.ru ), Powerpoint animated presentations, subtitled videos, a documentreading camera, and so forth. Indiana University's Oncourse virtual workspace played an integral part in every class session, providing numerous benefits for learning.

This practice of bringing authentic cultural experiences into the classroom with the aid of information technology appears to be a common practice among the grammar instructors of SWSEEL. The current state of technology enables that to a considerable degree. A notable example is a teleconference with a surviving family member of a murdered journalist, organized via Skype by a lecturer in a weekly extracurricular seminar.

Nowhere, however, is the distributed nature of intelligence as evident as in the phonetics module of the course. Since placement tests do not have a phonetics component, phonetics instructors had to face the challenging task of working with students of very different backgrounds in phonetics in the same group. The phonetics module for Level 6 consisted of one weekly theoretical lecture and one weekly practice hour in lab. (Perhaps owing to the outgoing nature of the Level 6 group, even the weekly lectures became highly interactive, with students requesting 
clarifications of previously identified challenges and practicing aloud, and the instructor eagerly working with them. This is further testimony to the flexibility of the SWSEEL program.) During the lab, students practiced phonemes, and concluded with a recording that they submitted via IU Oncourse to the instructor. This enabled the instructor to manage the learning of diverse groups. This echoes the sentiment of Learning Sciences in general that instructional technology is a crucial component of learning, and illustrates Pea's (1993) point of intelligence being augmented by technology. Additionally, phonetics relies on inscriptional systems (e.g., International Phonetic Alphabet, IPA) to capture pronunciation, in accordance with Pea's (1993) notion that distributed intelligence is augmented by inscriptional systems.

\section{Small groups: advantages and disadvantages}

Small-group activities are relevant not only for classes with large numbers of students but also for relatively small classes of intensive summer language programs. Such activities save classroom time in comparison with all-class activities, during which everyone is forced to listen to a language performance (e.g., either reading or speaking) of only one student at a time. When splitting the class into numerous small groups, it is possible to productively engage the entire class at the same time. Further, work in small groups fosters students' engagement. Additionally, from the perspective of the instructor, it is easier to control the activity in smaller groups of students than it is in larger groups. In larger groups, not all students have to be participating, whereas in a small group lack of engagement quickly becomes noticeable.

Typical small group activities in the SWSEEL Russian Level 5 included dialogues based on a range of topics, structured interviews with a preset list of questions, a "speed-dating" role-playing game, fill-in-the-blanks on handouts in pairs, vocabulary-based guessing games in small groups of three to four, etc. Learning in small groups is usually perceived as advantageous. However, taking a sociocultural perspective, we should be aware of the increased importance of the classroom environment in small groups. For example, one of the challenges of learning Russian is learning the correct stress. Stress is normally not marked in the written text, at least not in authentic texts. Compounding the difficulty, there are no definitive rules regarding the placement of stress. L1 speakers simply have a feel for it. Unfortunately, learners do not. For this reason, a disadvantage of working in small groups is that the learners are likely to pick up incorrect stress from each other. The instructor cannot monitor every word being said while the entire class, divided into small groups, works in parallel. Moreover, taking into account the unusually large number of classroom hours and increased pressure and stress in intensive programs, we must be aware of possible psychological problems that might occur in small classrooms due to student incompatibility or other individual learning factors. 


\section{Designing for motivation}

The SWSEEL program has an advantage over a typical college language course environment due to the unique nature of its participants. The students who enroll in SWSEEL typically enter the program highly self-motivated to make the most of the course. Nevertheless, even with this favorable initial condition, designing for motivation is important to examine.

As the description of SWSEEL implies, this intensive summer program can be grueling and exhausting for both learners and teachers, and in our experience, the second half of the summer, in particular, can be marked by fatigue. Design principles that foster engagement are, therefore, critical. Engagement can be enhanced by giving students authority over formulating classroom tasks and homework. When students are allowed to actively choose the problem they work on, they are more likely to be interested in it. However, it is important that students have adequate access to resources for learning, as well as being allowed sufficient time to complete tasks (Engle \& Conant, 2001).

The Russian instructors at SWSEEL strive to provide opportunities for student autonomy within the restrictions of the fast-paced, intensive learning environment. In the experience of the article authors, Russian Level 5B students had a certain amount of autonomy throughout the course by being able to choose the major focus of their homework, presentations, and projects that would fit their personal interests. Some homework tasks allowed choosing between different types of activity (either reading or writing). For weekly 5-7 minute presentations, students chose topics related to the major lexical theme of the week and used textbook vocabulary for the week. The grammar instructor tried to avoid giving full autonomy to students by localizing and charging the driving project question or topic (see the discussion of project-based learning in Larmer, Ross, \& Mergendoller, 2009), in order to make a project be more engaging for students while facilitating the process of topic choosing. Likewise, SWSEEL Russian instructors have a considerable amount of autonomy in choosing the teaching materials in order to increase the dynamics of the learning process in class.

However, identical practical tasks might be accepted by different groups of students with varied amounts of enthusiasm and engagement. The same learning activities could produce very different responses and results from different groups. For example, grammar instructors of SWSEEL Level 5A and Level 5B shared materials they had created, and then shared observations on how such materials were received by their students. As a result, it became clear that groups' reactions varied depending on the preferences of students as a group. For instance, while one group preferred conversations, another group had a strong preference for fill-inthe-blanks tasks. This reflection on the role of group dynamics in determining student preferences was shared by a listening instructor. Her observation is valuable due to the specific teaching context for this instructor, as she worked with the same materials in two different groups of the same level, thus having an opportunity to compare learners' preferences as groups. It is interesting that materials that one group liked were off-putting or too difficult for another group, 
and exercises that one group would find boring would be very engaging for the other group.

We would like to return to the question of adequate resources impacting motivation. Particularly the time element requires a delicate balance in a SWSEEL course. Undeniably, part of the students' weariness can be attributed to their devotion to reviewing what has been covered in the class each day and their diligence in doing their homework. On the other hand, without the reinforcement of students' independent extracurricular work, the intensive course would not be as efficient. Providing adequate but not exhausting homework assignments, therefore, poses yet another challenge for the SWSEEL instructors.

\section{Assessment Consistent with Sociocultural Learning Capture}

The SWSEEL program employs a whole spectrum of student assessment. Much of the assessment is used for formative purposes, not surprisingly, given the intense, dynamic nature of the program. A formative assessment takes place when a teacher seeks to respond to student work, making judgments about what has been grasped and what has not, with an intention of improving that learning. As summative assessments in her class, one of the article authors, a grammar instructor, used two major exams (a midterm and a final), weekly two-hour tests with written and oral parts, and weekly vocabulary and grammar quizzes. As a student in the Level 6 grammar module, the other article author encountered a slightly different summative assessment, in that the instructor did not employ vocabulary or grammar quizzes, but administered only written weekly tests, in addition to the midterm and final. While the instructor also assigned grades for homework, she emphasized that homework was primarily for learning.

In conclusion, while there are slight differences in the assessment as practiced by individual grammar instructors, overall a full spectrum of assessment instruments is utilized in the SWSEEL Russian language program.

\section{Concluding Remarks}

We have shown that the SWSEEL intensive Russian course is consistent with the design principles originating from sociocultural learning theories. In turn, there are insights in sociocultural learning theories that might offer practical suggestions for SWSEEL designers and instructors. Here we summarize the main points of how sociocultural theory frames a contemporary intensive Russian course such as SWSEEL, and provide recommendations for further research.

We argue that the strength of SWSEEL lies in its flexibility. It offers a plethora of learning environments that accommodate learners of numerous interests and learning preferences, allow for authentic practices, learning through inquiry, and cognitive apprenticeship. With a program this intensive, a challenge for instructors is to weigh the time needed to adequately satisfy classroom requirements (i.e., homework and review of class work) against the benefits of students participating in informal learning environments. In some instances, students felt they would not have enough time to take part in interest-driven clubs. This might be more difficult 
for the advanced intermediates than for advanced or novice learners. Novice learners are not yet at a level where they can take advantage of activities such as lectures in the target language, and advanced students can participate in these more or less effortlessly. In contrast, advanced intermediates have just reached the level where they can attend the lectures, but not without exerting effort.

This paper is a first step, analogous to a feasibility study. We only briefly touched on the role of technology in SWSEEL. Learning Sciences is a multidisciplinary field, and expanding our understanding of learning as it happens in diverse environments, in vivo so to speak, is only one of its missions. The other, equally important, mission is advancing learning through design. One of Learning Science's main components, alongside cognitive psychology, sociology and education, is computer science and instructional technology. With the strong emphasis on utilizing technology for the advancement of learning, Learning Sciences may be of use to the intensive language programs where technology, as we established, opens new, unprecedented possibilities. Having established the suitability of this framework, the next step is more research concentrating on the design component.

\section{References}

Bredo, E. (2006). Philosophies of educational research. In J. L. Green, G. Camilli, \& P. B. Elmore (Eds.), Handbook of complementary methods in education research (pp. 3-31). Hillsdale, NJ: American Educational Research Association/ Lawrence Erlbaum.

Brown, J. S., Collins, A., \& Duguid, P. (1989). Situated cognition and the culture of learning. Educational Researcher, 18(1), 32-42.

Case, R. (1996). Changing views of knowledge and their impact on educational research and practice. In D. R. Olson, \& N. Torrance (Eds.), The handbook of education and human development (pp. 76-99). Oxford, UK: Blackwell.

Engle, R. A., \& Conant, F. R. (2002). Guiding principles for fostering productive disciplinary engagement: Explaining an emergent argument in a community of learners classroom. Cognition and Instruction, 20(4), 399-483.

Greeno, J. G. (1997). On claims that answer the wrong questions. Educational Researcher, 26(1), 5-17.

Greeno, J. G., Collins, A. M., \& Resnick, L. (1996). Cognition and learning. In D. C. Berliner \& R. C. Calfee (Eds.), Handbook of educational psychology. New York, NY: Simon \& Schuster Macmillan.

Greeno, J. G., \& Middle School Mathematics Through Applications Project Group (1998). The situativity of knowing, learning, and research. American Psychologist, 53(1), 5. 
Hickey, D. T., \& Anderson, K. T. (2007). Situative approaches to assessment for resolving problems in educational testing and transforming communities of educational practice. In P. Moss (Ed.), Yearbook of the National Society for the Study of Education: Evidence and Decision Making, 106(1), 269-293.

Lantolf, J. P. (Ed.). (2000). Sociocultural theory and second language learning. Oxford, UK: Oxford University Press.

Lantolf, J. P., \& Thorne, S. L. (2007). Sociocultural theory and second language learning. In B. VanPatten \& J. Williams (Eds.), Theories in second language acquisition: An introduction (pp. 201-224). Hillsdale, NJ: Lawrence Erlbaum.

Larmer, J., Ross, D., \& Mergendoller, J. R. (2009). PBL Starter Kit. Novato, CA: Buck Institute for Education.

Leont'ev, A. N. (1974). The problem of activity in psychology. Journal of Russian and East European Psychology, 13(2), 4-33.

Pea, R. D. (1993). Practices of distributed intelligence and designs for education. In G. Solomon (Ed.), Distributed cognitions: Psychological and educational considerations (pp. 47-87). Cambridge, UK: Cambridge University Press.

Rifkin, B. (1996). Grammatika v kontekste: Russian grammar in literary contexts. New York, NY: McGraw-Hill Humanities/Social Sciences/Languages.

Rogoff, B. (1990). Apprenticeship in thinking: Cognitive development in social contex. New York, NY: Oxford University Press.

Sawyer, R. K. (2005). The Cambridge handbook of the learning sciences. Cambridge, UK: Cambridge University Press.

Tarone, E. (2007). Sociolinguistic approaches to second language acquisition research, 1997-2007. The Modern Language Journal, 91(s1), 837-848.

Thorne, S. L. (2005). Epistemology, politics, and ethics in sociocultural theory. The Modern Language Journal, 89, 393-409.

Vygotsky, L. S. (1978). Mind in society: The development of higher psychological processes. Ed. M. Cole, V. John-Steiner, S. Scribner, \& E. Souberman. Cambridge, MA: Harvard University Press.

Vygotsky, L. S. (1987). The collected works of L. S. Vygotsky, volume 1: Problems of general psychology. Ed. R. Reiber \& A. Carton. New York, NY: Plenum Press. 